\title{
A Simplified Method for Analysis of Laterally Loaded Piles considering Cyclic Soil Degradation
}

\author{
Yuzhe Yang $\mathbb{D},{ }^{1}$ Xiaodong Gao $\mathbb{D}^{1,},^{1,2}$ Wenbing $W u\left(\mathbb{D},,^{1,3}\right.$ and Kangyu Xing ${ }^{1}$ \\ ${ }^{1}$ Engineering Research Centre of Rock-Soil Drilling and Excavation and Protection, Ministry of Education, \\ China University of Geosciences, Wuhan, Hubei 430074, China \\ ${ }^{2}$ Office of the Discipline Inspection Commission, China University of Geosciences, Wuhan, Hubei 430074, China \\ ${ }^{3}$ Zhejiang Institute, China University of Geosciences, Hangzhou 311305, China \\ Correspondence should be addressed to Xiaodong Gao; gaoxingzi2019@126.com and Wenbing Wu; zjuwwb1126@163.com
}

Received 12 May 2021; Accepted 16 June 2021; Published 5 July 2021

Academic Editor: Guang-Liang Feng

Copyright (C) 2021 Yuzhe Yang et al. This is an open access article distributed under the Creative Commons Attribution License, which permits unrestricted use, distribution, and reproduction in any medium, provided the original work is properly cited.

\begin{abstract}
This paper proposes a simplified method to analyze the bearing behavior of pile undergoing cyclic lateral load. Firstly, a modified strain model is proposed by utilizing the Duncan-Chang model to describe the stress-strain behavior of soils in the strain wedge. Then, a cyclic degradation model of soft clay considering the accumulation of plastic strain and pore water pressure is presented based on the cyclic triaxial test. Combining with the modified strain wedge model and degradation model of soil, a simplified method is established for the cyclic laterally loaded pile. The accuracy of the present method is verified by comparing it with existing model tests. The results show that the pile lateral displacement and strain wedge depth increase with the number of cycles and cyclic load amplitude. It is necessary to consider the effect of cumulative pore water pressure during the analysis of cyclic laterally loaded pile embedded in soft clay.
\end{abstract}

\section{Introduction}

Piles supporting offshore engineering structures are mainly subjected to cyclic lateral loads, such as wind, waves, and currents, which may cause large lateral displacements of pile body and attenuation of bearing capacity. The major reason for these phenomena is that the soil strength would be degraded due to the accumulation of plastic strain caused by cyclic loads [1]. Many precious approaches have been proposed to investigate the bearing behavior of pile under cyclic lateral loads, including simplified $p-y$ curve methods [2-4] and finite element methods [5-8]. The mentioned simplified $p-y$ methods consider soil degradation by scaling down the ultimate lateral resistance of soil or the stiffness of $p-y$ curve. However, these $p-y$ curve methods may not be applicable to offshore piles under cyclic loads with a large number of cycles, for they are mainly proposed based on the lateral loading tests of small-diameter pile under small cycle numbers, without directly considering the effect of cyclic loading amplitude and cycle number [9]. Based on degradation stiffness model in sand, Achmus et al. [6] and $\mathrm{Hu}$ et al. [7] developed finite element methods to study the bearing behavior of pile under cyclic lateral loads. The most important advantage of these finite element methods is that they can determine the stress distribution and degree of soil degradation of pile surrounding soil. However, their calculation process is much more complicated and not conducive to engineering applications. In addition, the above studies have been mostly conducted on sand, which may be not suitable for the piles in soft clay. Compared with rigid pile in sand $[6,7,10]$, piles installed in soft clay often behave as flexible soil-pile systems [11], and the accumulation of pore water pressure in soft clay cannot be ignored for it would cause the degradation of soil strength [12].

Unlike the complicated finite element methods, Norris [13] originally proposed the strain wedge model (SW model), which can obtain the stress distribution of pile surrounding soil, to calculate the appropriate reaction modulus of pile surrounding soil from the soil strain in the three-dimensional passive wedge in uniform soil. 
Subsequently, Ashour et al. [14] extended Norris's method to deal with layered soil in the strain wedge. However, the used stress-strain relation in Norris's method was developed based on limited experiment data and difficult to be applied in the analysis of pile under cyclic lateral loads [15]. Besides, the assumption of linear displacement of piles in SW model would cause some contradictions with the actual bearing behavior of piles [16].

The objective of this study is to investigate the bearing behavior of laterally loaded piles considering cyclic soil degradation. A modified SW model is introduced to examine the stress distribution of pile surrounding soil. Besides, a cyclic degradation model of soft clay considering the accumulation of plastic strain and pore water pressure is proposed based on cyclic triaxial tests. Then, a simplified method to analyze the bearing behavior of piles under cyclic lateral loads is presented by applying the cyclic degradation model into the modified SW model. Finally, the proposed simplified method is verified by comparing the model predictions with results obtained from model tests.

\section{Modified Strain Wedge Model}

2.1. Basic Concept of SW Model. The aim of SW model proposed by Ashour et al. [14] is to determine the subgrade reaction modulus in the following differential equation:

$$
\mathrm{EI} \frac{\mathrm{d}^{4} y}{\mathrm{~d} z^{4}}+k(z) y=0,
$$

where EI and $y$ denote the flexural stiffness and lateral deflection of pile, respectively, and $k(z)$ is the subgrade reaction modulus at a depth of $z$, which is defined as follows:

$$
k=\frac{p}{y} \text {, }
$$

where $p$ is the soil resistance per unit length of pile and can be calculated by SW model.

As shown in Figure 1, a three-dimensional passive wedge of soil is developed in front of the deflected pile in SW model. The passive soil wedge is described by the base angle $\beta_{m}$, fan angle $\varphi_{m}$, and depth of the passive wedge $H$. The pile embedded length is $L$, and the depth of the passive wedge $H$ is equivalent to the depth of first zero-deflection point of pile. The lateral deformation of pile is assumed to vary linearly with depth, and the rotation angle of pile $\delta$ is consistent along pile shaft (see Figure 1(b)) [14]. The soil stress condition in the passive wedge can be determined by using triaxial test. The lateral earth pressure coefficient $K_{0}$ can be assumed to be 1 owing to pile driving effect. Hence, the major principle stress change in the direction of pile movement $\Delta \sigma_{h}$ is equal to the deviatoric stress in the triaxial test, and vertical stress $\sigma_{v}$ in the subgrade is taken as confining stress in the triaxial test. With the increase of the lateral load acting on the pile head, the size and stress level of passive soil wedge would change accordingly. $\varphi_{m}$ also denotes the mobilized internal friction angle of soil. The relationship of $\beta_{m}$, width of the wedge face BC at depth $z$, and $\varphi_{m}$ can be obtained as follows [14]:

$$
\begin{aligned}
& \beta_{m}=45^{\circ}+\varphi_{m}, \\
& \mathrm{BC}=D+(H-z) \tan \varphi_{m} \tan \beta_{m},
\end{aligned}
$$

where $D$ represents the diameter of pile. For square piles, $D$ can be calculated in the form of equal perimeter.

The soil resistance $p$ at depth $z$ is written as follows:

$$
p=S_{1} \mathrm{BC} \Delta \sigma_{h}+2 S_{2} D \tau
$$

where $S_{1}$ and $S_{2}$ are pile shape factors which equal 0.75 and 0.5 for circular pile, and both equal 1 for square pile, respectively. $\tau$ denotes the mobilized pile side shear stress, which can be calculated as follows [14]:

$$
\frac{\tau}{\tau_{\text {ult }}}= \begin{cases}12.9 y D-40.5 y^{2} D^{2}, & (x<6 \mathrm{~m}), \\ 32.3 y D-255 D^{2}, & (x>6 \mathrm{~m}),\end{cases}
$$

where the units of $y$ and $D$ are centimeter and meter, respectively. $\tau_{\text {ult }}$ is the ultimate shear stress of surrounding soil acting on pile shaft and given as $\tau_{\text {ult }}=\zeta S u$, in which $S u$ and $\zeta$ are undrained shear strength and adhesion factor, respectively. $\zeta$ is equal to $0.5,1-\left(S_{u}-25\right) / 90$ and 0.5 for $S_{u} \leq 25 \mathrm{kPa}, \quad 25 \mathrm{kPa}<S_{u} \leq 70 \mathrm{kPa}$, and $S_{u}>70 \mathrm{kPa}$, respectively.

2.2. Modifications of SM Model. The modifications of SM model mainly include two aspects: (1) based on the nonlinear deformation assumption of single pile, the relationship between lateral deflection of pile and lateral strain of soil in passive wedge is established; (2) the Duncan-Chang model is introduced to describe the stress-strain relationship of clay.

In the SM model proposed by Norris's group $[13,14]$, the lateral deformation of pile is assumed to vary linearly with depth, and the rotation angle of pile $\delta$ is consistent along pile shaft (see Figure 2(a)). However, the actual rotation angle of the lower part of pile should be less than the assumed one, which would lead to a discrepancy with the actual conditions $[15,16]$. Therefore, this work introduces the nonlinear deformation assumption proposed by Xu et al. [16] for laterally loaded pile in sand. As shown in Figure 2(b), the strain wedge-pile system is divided into a series of segments or layers with thickness $h$. The strain of the $i$ th strain wedge is $\varepsilon_{i}$, and the displacements at the upper and lower interfaces of the $i$ th pile segments are $y_{i-1}$ and $y_{i}$, respectively. The rotation angle of pile is assumed to vary with depth and satisfy the following equation:

$$
\begin{aligned}
\delta_{i} & =\left(\frac{\mathrm{d} y}{\mathrm{~d} z}\right)_{i}, \\
& =\frac{y_{i-1}-y_{i}}{h} .
\end{aligned}
$$

Meanwhile, the rotation angle also has the following relationship with $\varepsilon_{i}$ and $\varphi_{m i}[13]$ : 


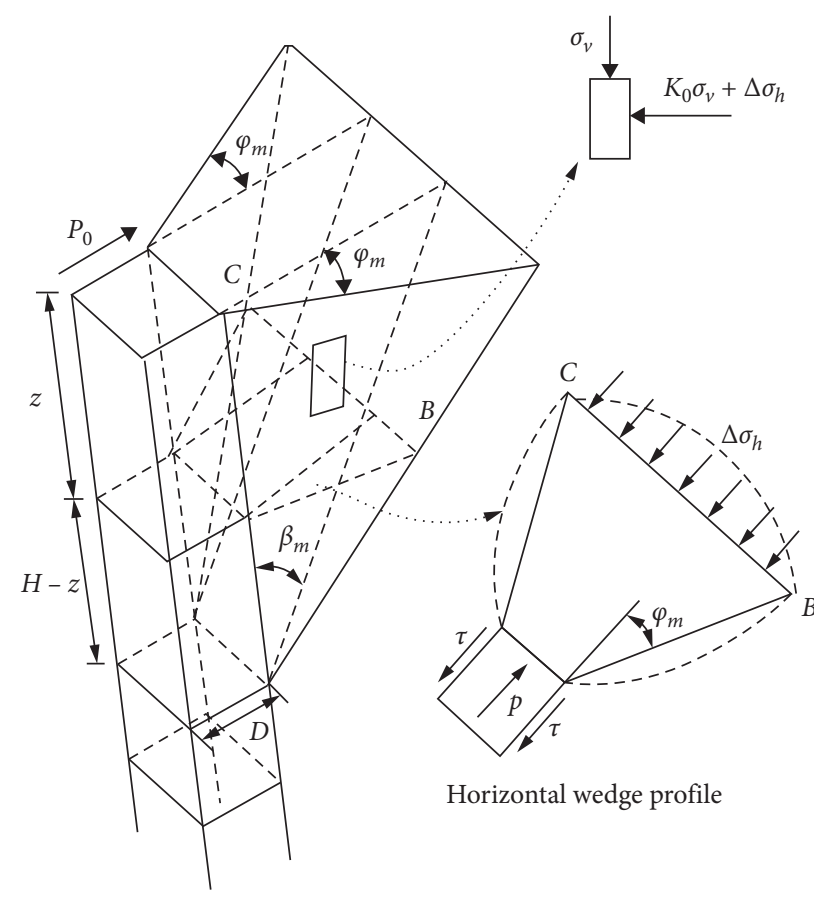

(a)

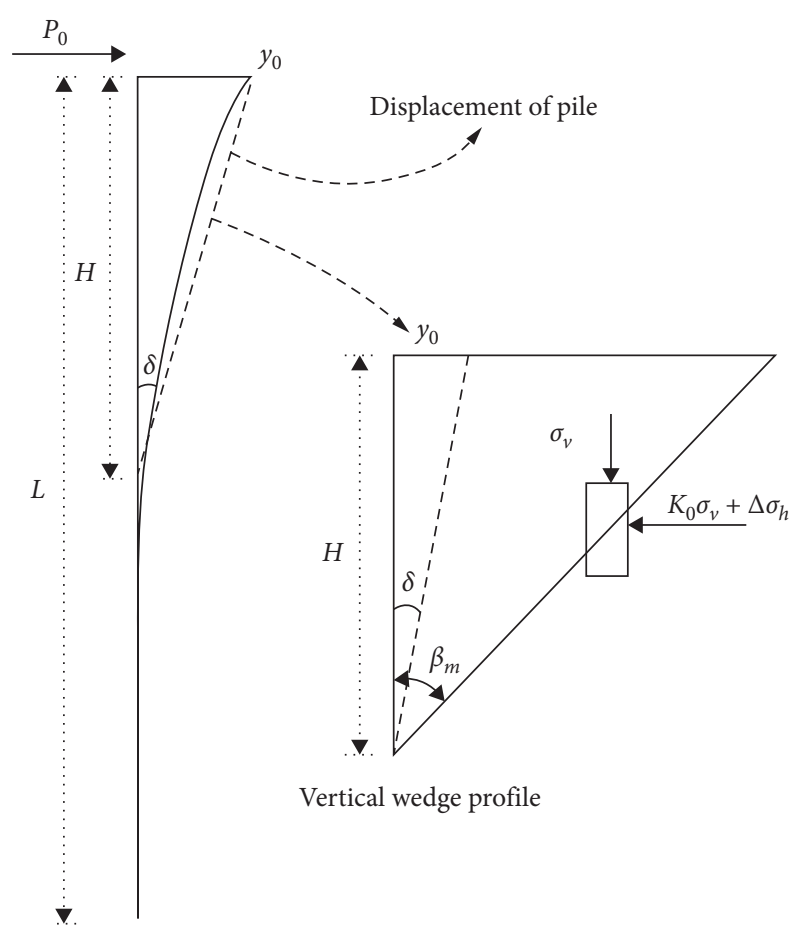

(b)

Figure 1: Basic strain wedge model [14]. (a) Three-dimensional wedge in front of pile. (b) Deformation of pile and vertical wedge profile.

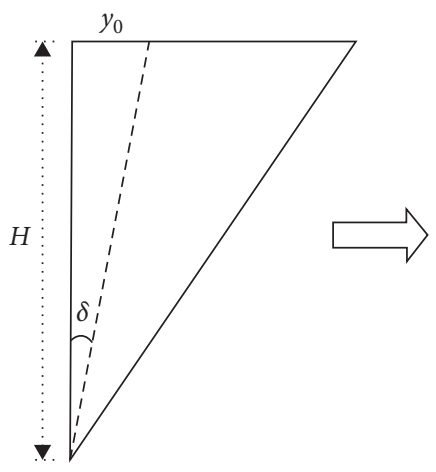

(a)

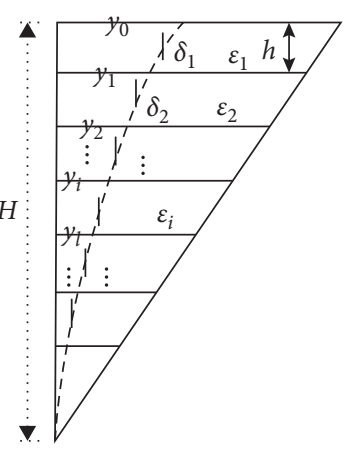

(b)
FIGURE 2: Displacement distribution of pile in SW model. (a) Linear displacement of pile in SWM. (b) Nonlinear displacement of pile in SWM.

$$
\begin{aligned}
\delta_{i} & =\frac{\gamma_{i}}{2} \\
& =\frac{\left(1+v_{i}\right) \varepsilon_{i}}{2} \cos \varphi_{m i},
\end{aligned}
$$

where $\gamma_{i}$ and $\nu_{i}$ are the shear strain and Poisson's ratio of the $i$ th soil layer, respectively. $\varphi_{m i}$ is the fan angle of the $i$ th passive soil wedge.

Then, the Duncan-Chang model [17] is used to obtain the $\Delta \sigma_{h} \sim \mathcal{E}$ relationship as follows:

$$
\Delta \sigma_{h_{i}}=\frac{\varepsilon_{i}}{\left(1 / E_{\text {ini }}\right)+\left(R_{f} \varepsilon_{i} / \Delta \sigma_{\mathrm{hfi}}\right)},
$$

where $R_{f}$ is the failure ratio within the range of $0.75-1$. $E_{\text {ini }}=K_{e} P_{a}\left(\sigma_{v i}^{\prime} / P_{a}\right)^{n}$ denotes the initial elastic modulus, in which $K_{e}$ and $n$ are the calculated parameters within the range of 20-200 and $0.5-0.8$ for clay [18], respectively. $P_{a}=$ $101 \mathrm{kPa}$ represents the standard atmospheric pressure. $\Delta \sigma_{\mathrm{hfi}}$ is the deviatoric stress $\sigma_{\text {sfi }}$ at failure and can be expressed as follows:

$$
\begin{aligned}
\Delta \sigma_{\mathrm{hfi}} & =\left.\sigma_{\text {sfi }}\right|_{\text {failure }}, \\
& =\frac{2 c_{i} \cos j_{i}+2 \sigma_{v i} \sin j_{i}}{1-\sigma_{v i} \sin j_{i}},
\end{aligned}
$$

where $c_{i}$ and $\varphi_{i}$ are the cohesion and internal friction angle of the $i$ th soil layer, respectively, which can be determined by unconsolidated undrained (UU) triaxial test.

The mobilized internal friction angle $\varphi_{m i}$ can be determined according to the stress level of soil in strain wedge (see Figure 3):

$$
\sin \varphi_{m i}=\frac{\Delta \sigma_{h i}}{\Delta \sigma_{h i}+2 \sigma_{v i}+\left(2 c_{i} / \tan \varphi_{i}\right)} .
$$

With the increase of lateral load, the stress level of soil in strain wedge increases continuously until approaching the ultimate state. Then, the soil reaction at pile side reaches the ultimate soil resistance $p_{u}$ and can be expressed as follows [19]:

$$
p_{u}=\left(S_{1} 10 S_{u}+S_{2} 2 S_{u}\right) D .
$$




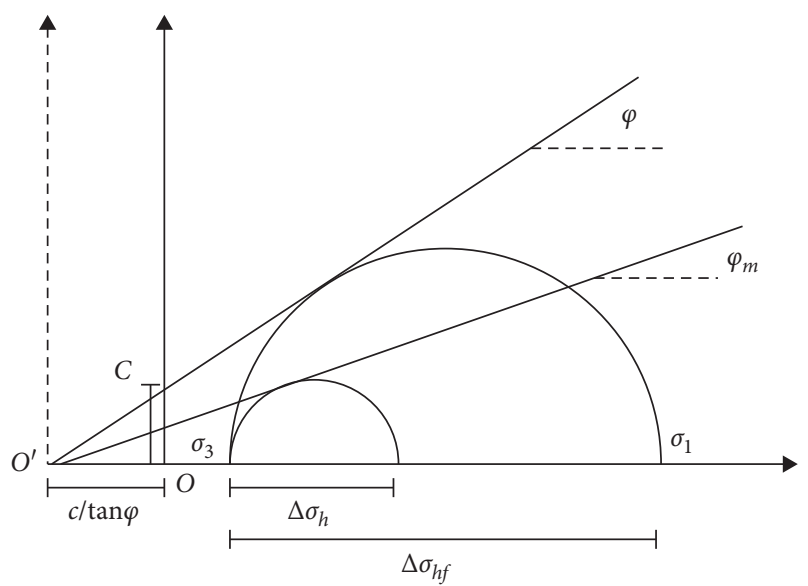

FIGURE 3: Relationship between friction angle and stress level of soil.

2.3. Calculation of SM Model. The finite difference method is used to solve (1), and the soil-pile system is evenly divided into $N_{L}(=L / h)$ elements or layers with thickness $h$, and the soil-pile system within strain wedge range is divided into $N_{H}(=H / h)$ segments. Combining with the lateral force and bending moment constraints of pile head and pile end, the differential solution equations of pile-strain wedge system are expressed as follows:

$$
[K][Y]=[P],
$$

where $[K]$ is the pile stiffness matrix of order $(N+1) \times(N+1)$. [Y] and $[P]$ are the vectors of pile displacement and lateral load of $(N+1)$, respectively. The specific solution of (12) can be referred to in [20, 21].

Combining equation (4) and equations (6) and (7), the subgrade reaction modulus of soil within the depth of strain wedge can be obtained as follows:

$$
k_{i}=\frac{p_{i}}{\left(y_{i-1}+y_{i}\right) / 2}, \quad 1 \leq i \leq N_{H}
$$

The subgrade reaction modulus below the strain wedge varies linearly with depth and can be expressed as follows:

$$
k_{i}=\eta_{h} z, \quad N_{H}<i \leq N_{L},
$$

where $\eta_{h}$ is the coefficient of the subgrade reaction [22].

Figure 4 shows the specific process for solving the static response of laterally loaded pile by utilizing the modified SM model. The corresponding computational program has developed using MATLAB software [23]. Based on the proposed procedure, the stress and strain levels of pile surrounding soil under different load levels can be determined for different depths. To facilitate calculation, the initial displacement value of pile in Figure 4 can be determined according to the solution solving by elastic-plastic analyzing method [24].

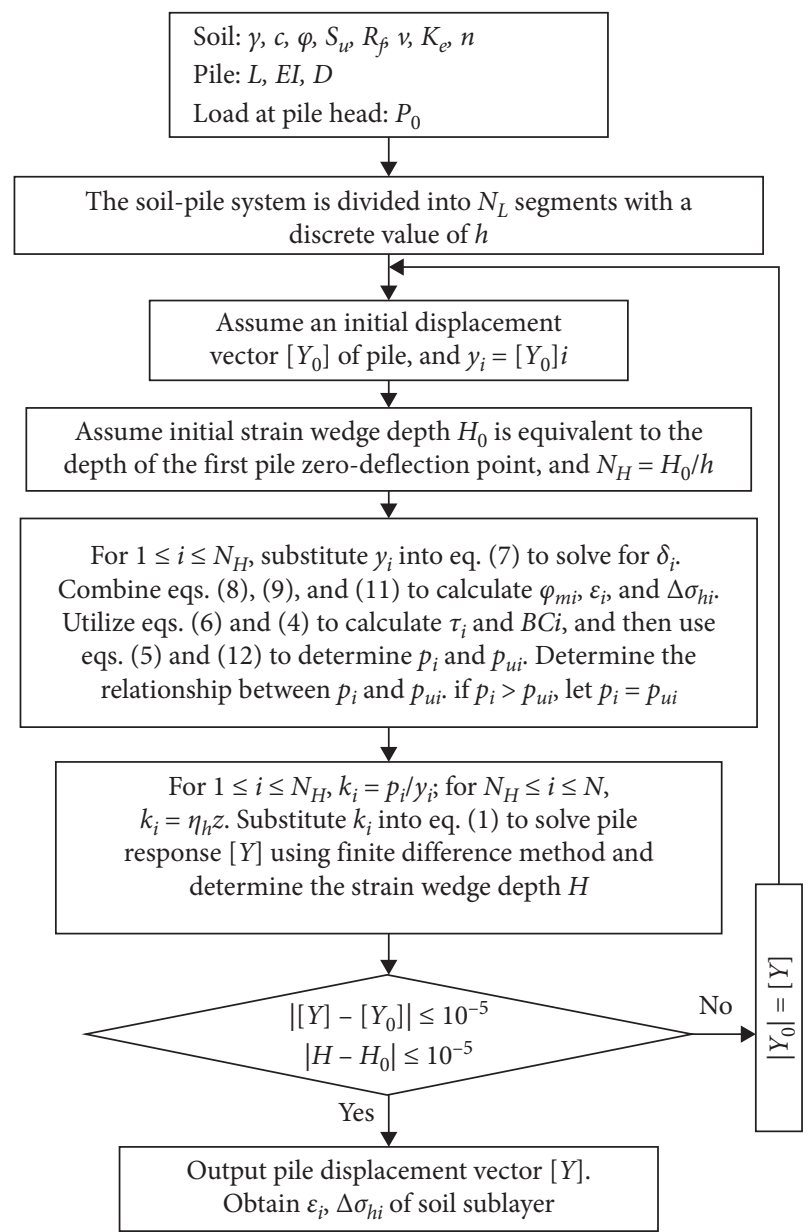

FIGURE 4: Flowchart for procedure of modified SW model.

\section{Degradation Model of Soft Clay under Cyclic Loading}

For the lateral loading conditions, the stress states of soil in the strain wedge under static load are similar to the static triaxial test and undrained cyclic triaxial test, respectively. In other words, the vertical stress $\sigma_{v}$ is equivalent to confining pressure and lateral stress increment is equivalent to cyclic deviatoric stress $\sigma_{\text {cyc }}$. During cyclic triaxial test, with the increase of the number of cycles, cumulative plastic strains and pore water pressure would occur in the soil sample, which leads to the decrease of effective stress and further causes the weakening of the secant stiffness of clay and the increase of pile lateral displacement. Assuming that the elastic strain can be negligible, the degradation of secant stiffness after $N$ cycles $E_{s N}$ can be described by the cumulative plastic axial strains and pore water pressure as follows:

$$
\begin{aligned}
\frac{E_{s N}}{E_{s 1}} & =\frac{\left(\sigma_{\mathrm{cyc}}-u_{N}\right) / \varepsilon_{N}^{a}}{\sigma_{\mathrm{cyc}} / \varepsilon_{N=1}^{a}}, \\
& \cong \frac{\sigma_{\mathrm{cyc}}-u_{N}}{\sigma_{\mathrm{cyc}}} \frac{\varepsilon_{p, N=1}^{a}}{\varepsilon_{p, N}^{a}},
\end{aligned}
$$


where $\varepsilon_{p, N=1}^{a}$ and $\varepsilon_{p, N}^{a}$ are the plastic strains of soil after first cycle and $N$ cycles of cyclic deviatoric stress $\sigma_{\text {cyc }}$, respectively. $\varepsilon_{N=1}^{a}$ and $\varepsilon_{N}^{a}$ are the vertical strains after first cycle and $N$ cycles, respectively. $u_{N}$ is the pore water pressure after $N$ cycles, and $E_{s 1}$ is the secant stiffness after the first cycle.

\subsection{Semiempirical Formulas for Cumulative Plastic Strain and} Pore Water Pressure of Soft Clay. According to (15), the cumulative plastic strain and pore water pressure are key parameters to determine the degradation degree of clay. Triaxial test results $[25,26]$ show that $\varepsilon_{p, N}^{a}$ and $u_{N}$ of soft clay are related to the amplitude of cyclic deviatoric stress and the number of cycles. Based on triaxial tests, many scholars have fitted the curves of $\varepsilon_{p, N}^{a} \sim N$ and $u_{N} \sim N$ to obtain the semiempirical calculation formulas of cumulative plastic strain and pore water pressure of soft clay, which have been widely applied in engineering [27-30]. Here, based on the results of cyclic triaxial test [25] and considering the increase of cumulative pore water pressure, two semiempirical formulas cumulative plastic strain and pore water pressure of soft clay are proposed as follows:

$$
\begin{gathered}
\varepsilon_{p, N}^{a}=\varepsilon_{p, N=1}^{a} N^{\left(a_{\varepsilon} \eta_{d}^{b_{\varepsilon}}\right)}, \\
u_{N}^{r}=u_{N=1}^{r} N^{\left(a_{u} \eta_{d}^{b_{u}}\right)},
\end{gathered}
$$

where $\eta_{d}=\sigma_{\text {cyc }} / \sigma_{s f}$ denotes the cyclic stress ratio of pile surrounding soil, that is, the ratio of cyclic deviatoric stress to ultimate static deviatoric stress which satisfies $\sigma_{s f}=\left(\sigma_{1}-\sigma_{3}\right)_{f}$. $u_{N}^{r}=u_{N} / \sigma_{3}$ and $u_{r}^{1}=u_{1} / \sigma_{3}$ denote the ratios of cumulative pore water pressure and initial pore water pressure to minor principal stress $\sigma_{3} . a_{\varepsilon}, b_{\varepsilon}, a_{u}$, and $b_{u}$ are corresponding fitting regression parameters, which can be determined by cyclic triaxial test. Then, $\varepsilon_{p, N=1}^{a}$ can be calculated as follows:

$$
\varepsilon_{p, N=1}^{a}=\frac{\sigma_{\mathrm{cyc}}}{E_{\mathrm{in}}\left(1-\sigma_{\mathrm{cyc}} / \sigma_{s f}\right)}-\frac{\sigma_{\mathrm{cyc}}}{E_{\mathrm{ur}}},
$$

where $E_{\text {ur }}$ is unloading elastic modulus and is 1 to 3 times of the initial elastic modulus $E_{\text {in }}$ [17].

\subsection{Determination and Validation of Semiempirical Formulas}

Parameters. Liu et al. [25] conducted a series of undrained cyclic triaxial tests on soft clay and obtained the cumulative plastic strain and pore water pressure curves of soil under different cyclic stress ratios. The parameters of equations (16) and (17) can be obtained by fitting the test results. Typical regression parameters are found for cumulative plastic strain to be $a_{\varepsilon}=0.594$ and $b_{\varepsilon}=1.908$, and for cumulative pore water pressure to be $a_{u}=0.828$ and $b_{u}=1.124$. Then, the regression equation of the initial pore water pressure ratio is expressed as follows:

$$
u_{1}^{r}=0.06125 \eta_{d}^{1.6085} \text {. }
$$

Equations (16) and (17) with the given parameters are used to fit the results of cyclic triaxial tests by Liu et al. [25], and the fitting results are shown in Figure 5. It is found that the two semiempirical formulas presented in this paper have sufficient accuracy and can better reflect the engineering characteristics of soft clay undergoing cyclic loads. Furthermore, substituting equations (16) and (17) into equation (15), the stiffness attenuation of soft clay can be reasonably simulated.

\section{Calculation Method of Pile Lateral Displacement under Long-Term Cyclic Loading}

In this section, the modified SM model and degradation model of soft clay are used to calculate the pile lateral displacement under long-term cyclic loading with the constant loading amplitude $P_{\max }$ and the number of cycles $N$. Firstly, based on the quasistatic method, the modified SM model is adopted to calculate the distribution law of stress and strain of pile surrounding soil undergoing the static load $P_{\text {max }}$ along the depth. Based on the stress state determined by the modified SM model, the distribution of cyclic stress ratio of pile surrounding soil can be obtained, and then the attenuation stiffness of soil after $N$ cycles can be calculated according to the degradation model of soft clay. Finally, the attenuation stiffness is introduced into the modified SW model to calculate the lateral displacement of pile. The specific calculation steps are as follows:

(i) Step 1. Determine $\eta_{d i}$. Let $P_{0}=P_{\max }$, and input the parameters of pile and soil into flowchart (Figure 4). Based on the modified SW model, the lateral displacement of pile under load $P_{0}$ is calculated. Then, the increment of lateral stress $\Delta \sigma_{h i}$ and lateral strain $\varepsilon_{i}$ of the $i$ th soil layer at different depths are obtained. Letting $\sigma_{\text {cyci }}=\Delta \sigma_{h i}$ and taking $\Delta \sigma_{h i}$ as the amplitude of cyclic deviatoric stress, the corresponding cyclic stress ratio of pile surrounding soil $\eta_{d i}=\sigma_{\text {cyci }} / \sigma_{\text {sfi }}$ is determined.

(ii) Step 2. Determine $\varepsilon_{p i, N}^{a}, u_{N i}$, and $E_{s N i}$. Calculate the cumulative plastic strain $\varepsilon_{p i, N}^{a}$ and cumulative pore water pressure $u_{N i}$ of the $i$ th soil layer in strain wedge subjected to different cyclic stress ratios by using equations (16) and (17). Then, substituting $\varepsilon_{p i, N}^{a}$ and $u_{N i}$ into equation (15), the attenuation stiffness $E_{s N i}$ of the $i$ th soil layer in strain wedge after $N$ cycles can be obtained.

(iii) Step 3. Determine the stress-strain relationship of each soil layer during the $N$ th loading process. As shown in Figure 6, unlike the static loading process, the soil stiffness is attenuated due to the cumulative plastic strain and pore water pressure in soft clay. If the elastic strain during the reloading process is not considered, the stress-strain relationship of the $i$ th soil layer during the $N$ th loading process can be approximated as follows:

$$
\Delta \sigma_{h i}= \begin{cases}E_{s N i} \varepsilon, & \left(\varepsilon \leq \varepsilon_{p, N i}^{\mathrm{a}}\right), \\ \frac{\varepsilon}{\left(1 / E_{\mathrm{ini}}\right)+\left(R_{f} \varepsilon / \Delta \sigma_{\mathrm{hfi}}\right)}, & \left(\varepsilon>\varepsilon_{p, N i}^{\mathrm{a}}\right) .\end{cases}
$$




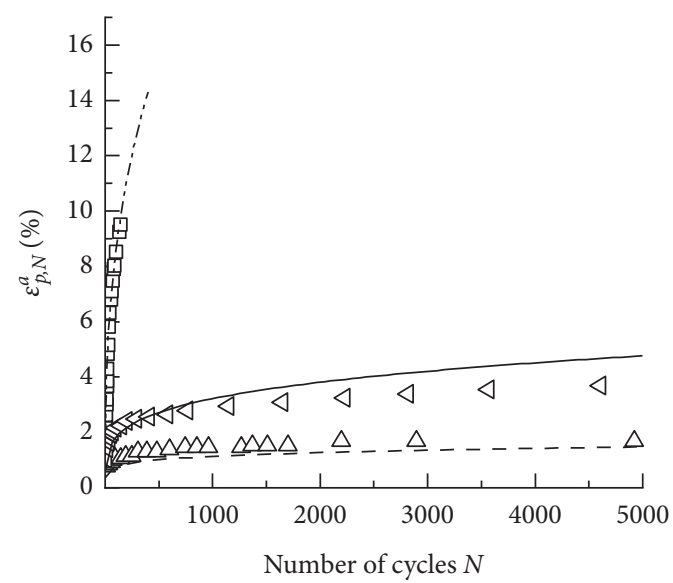

\begin{tabular}{|c|c|}
\hline Test result of [25] & Simulation curve \\
\hline $\begin{aligned} \square \sigma_{3} & =100 \mathrm{kPa} \\
\eta_{d} & =0.68\end{aligned}$ & $\begin{aligned} \cdots \sigma_{3} & =100 \mathrm{kPa}, \\
\eta_{d} & =0.68\end{aligned}$ \\
\hline $\begin{aligned} \Delta \sigma_{3} & =100 \mathrm{kPa} \\
\eta_{d} & =0.34\end{aligned}$ & $\begin{aligned}--\sigma_{3} & =100 \mathrm{kPa}, \\
\eta_{d} & =0.34\end{aligned}$ \\
\hline $\begin{aligned} \triangleleft \sigma_{3} & =50 \mathrm{kPa}, \\
\eta_{d} & =0.45\end{aligned}$ & $\begin{aligned} \sigma_{3} & =50 \mathrm{kPa} \\
\eta_{d} & =0.45\end{aligned}$ \\
\hline
\end{tabular}

(a)

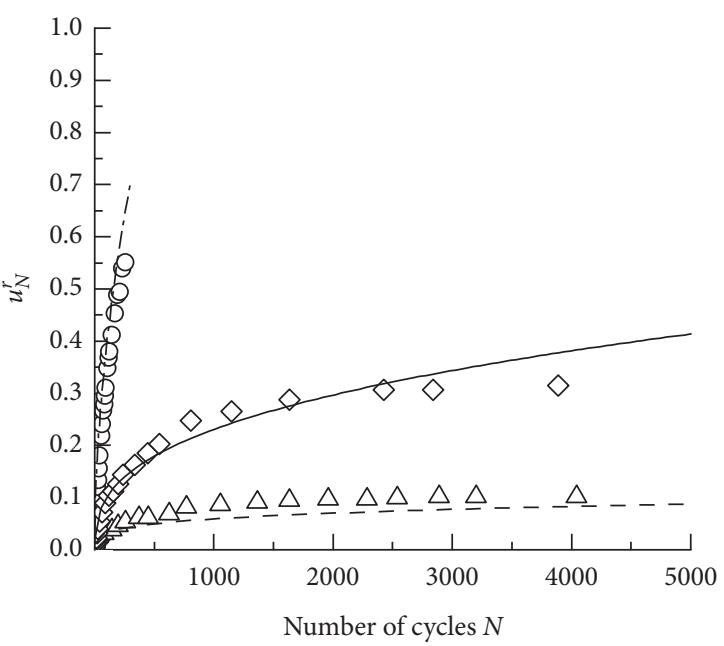

Test result of $[25$
$\begin{aligned} \sigma_{3} & =100 \mathrm{kPa} \\ \eta_{d} & =0.68 \\ \triangle \sigma_{3} & =100 \mathrm{kPa} \\ \eta_{d} & =0.34 \\ \diamond \sigma_{3} & =150 \mathrm{kPa} \\ \eta_{d} & =0.47\end{aligned}$

Simulation curve

-. $\sigma_{3}=100 \mathrm{kPa}$, $\eta_{d}=0.68$

$---\sigma_{3}=100 \mathrm{kPa}$, $\eta_{d}=0.34$

$-\sigma_{3}=150 \mathrm{kPa}$, $\eta_{d}=0.47$

(b)

Figure 5: Comparison between the results of prediction and cyclic triaxial test [25]. (a) Simulation of $\varepsilon_{p, N}^{a} \sim N$ curve. (b) Simulation of $u_{r}^{N} \sim$ Ncurve.

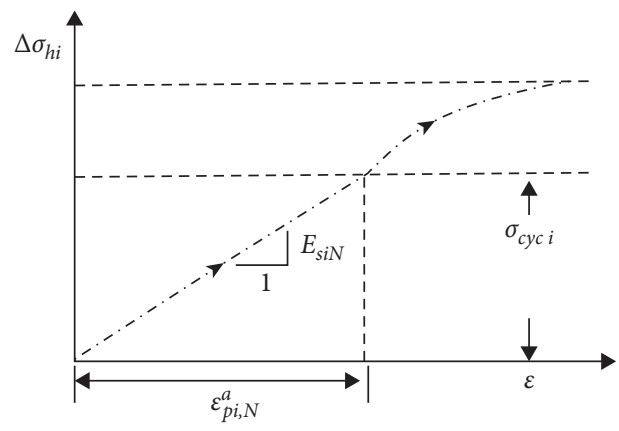

Figure 6: Relations of stress-strain of the soils during the $N$ thloading process.

(iv) Step 4. Letting $P_{0}=P_{\max }$, and replacing equation (20) with equation (8) and substituting it into the flowchart of SW model procedure to consider the effect of cyclic load, the lateral displacement and internal force of pile are calculated when there is lateral cyclic load acting on the pile head.

Based on the above four steps, the authors utilize MATLAB [23] to compile a corresponding calculation program for the analysis of laterally loaded piles considering cyclic soil degradation.

\section{Verification and Discussion}

In this section, a comparison with existing model tests is conducted to verify the proposed method. Liao et al. [11] carried out a series of $1 \mathrm{~g}$ model tests to study the response of flexible pile under static and one-way cyclic loading on marine clay. The model pile was a circular PVC tube with a total length of $1000 \mathrm{~mm}$ and an embedded length of $700 \mathrm{~mm}$. The outer diameter and wall thickness of the model pile are $50 \mathrm{~mm}$ and $5 \mathrm{~mm}$, respectively. The loading position is $100 \mathrm{~mm}$ below the pile head. The bending stiffness of model pile is $0.4 \mathrm{kN} \cdot \mathrm{m}^{2}$, and the unit weight of soil is $17.82 \mathrm{~kg} / \mathrm{m}^{3}$. The undrained shear strength of soil varies linearly with depth and can be expressed as $S_{u}=1.2+3.24 z$. The other selected parameters of soil are given in Table 1.

The present modified SW model is applied to calculate the load-displacement curve at loading position and displacement distribution of pile under different lateral cyclic loads. The comparison between the calculated results and test results are shown in Figure 7. It is noted that the results predicted by the proposed method are almost consistent with those results from tests. It also shows that the modified SW model can effectively simulate the bearing behavior of pile in soft clay under static lateral load.

When the lateral displacement of pile at the loading position is $0.2 \mathrm{D}$, the pile reaches the ultimate bearing state [31]. According to Figure 7, the ultimate static lateral 
TABLE 1: Parameters of soil.

\begin{tabular}{lccccc}
\hline$c(\mathrm{kPa})$ & $\varphi\left(^{\circ}\right)$ & $\nu$ & $K_{e}$ & $n$ & $\eta_{h}\left(\mathrm{kN} / \mathrm{m}^{3}\right)$ \\
\hline 0.82 & 17.4 & 0.49 & 100 & 0.68 & 6000 \\
\hline
\end{tabular}
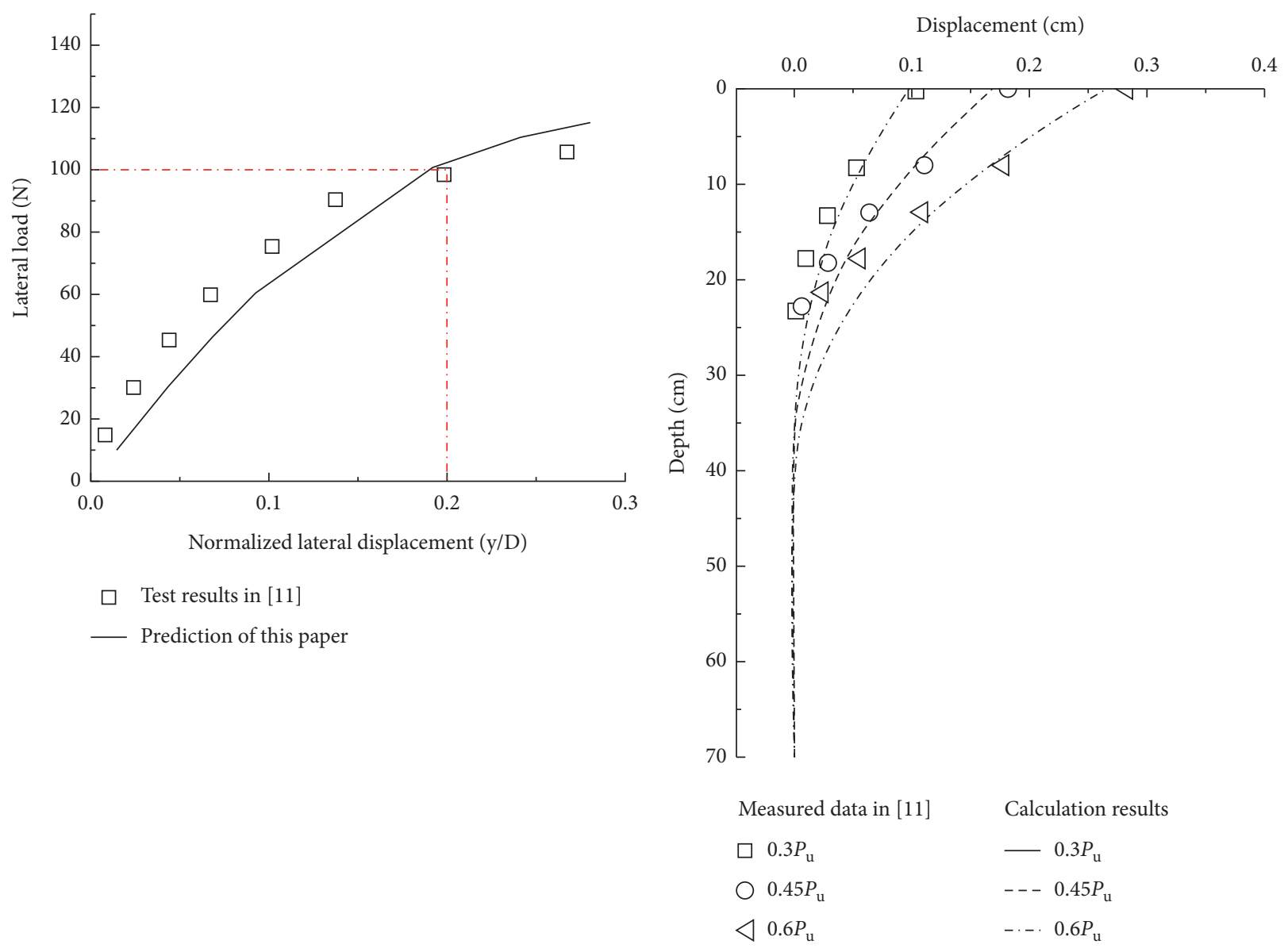

(a)

(b)

FiguRE 7: Comparison of measured data [11] with calculated results in static test. (a) Load-displacement curve at loading position. (b) Displacement distribution of pile.

capacity of the model pile $P_{u}$ is approximately $100 \mathrm{~N}$. In literature [11], three sets of cyclic loading tests with the loading amplitudes of $0.3 P_{u}, 0.45 P_{u}$, and $0.6 P_{u}$ were also carried out by one-way cyclic loading. The proposed method is applied to fit these tests and validate itself. Since the engineering properties of the test soil are similar to the soil sample of the cyclic triaxial test in literature [25], those fitting parameters in literature [25] are used in this fitting process. As well known, clay in different regions has different cyclic softening characteristics. For specific cases of cyclic laterally loaded pile, the fitting parameters of cyclic degradation model should be obtained by cyclic triaxial test on insite sample. The proposed fitting parameters are only for reference.

Figure 8 depicts the comparison between the results calculated by the present method and the test results under different cyclic loading amplitudes. As shown in Figure 8, $y^{1}$ and $y^{N}$ are the peak lateral displacement of the pile at loading position after the 1 st cycle and the Nth cycle, respectively. $y^{N} / y^{1}$ represents the development degree of displacement and can reflect the softening degree of pile lateral stiffness; that is, $\left(P_{\max } / y^{N}\right) /\left(P_{\max } / y^{1}\right)=y^{1} / y^{N}$.

It is found that the results obtained by the present method are in good agreement with the test results. As the number of cycles and the load amplitude increase, the lateral displacement of pile shaft increases, but the pile lateral stiffness decreases. This indicates that the simplified calculation method can reasonably reflect the development of pile lateral displacement and the degradation of pile lateral stiffness when the pile in soft clay is undergone long-term cyclic loading.

Figure 9 shows the influence of cumulative pore water pressure on the lateral displacement of pile. For the cases of cyclic load amplitude of $0.45 P_{u}$ and $0.6 P_{u}$, when the effect of cumulative pore water pressure on the stiffness of pile surround soil is considered, the development degrees of pile 


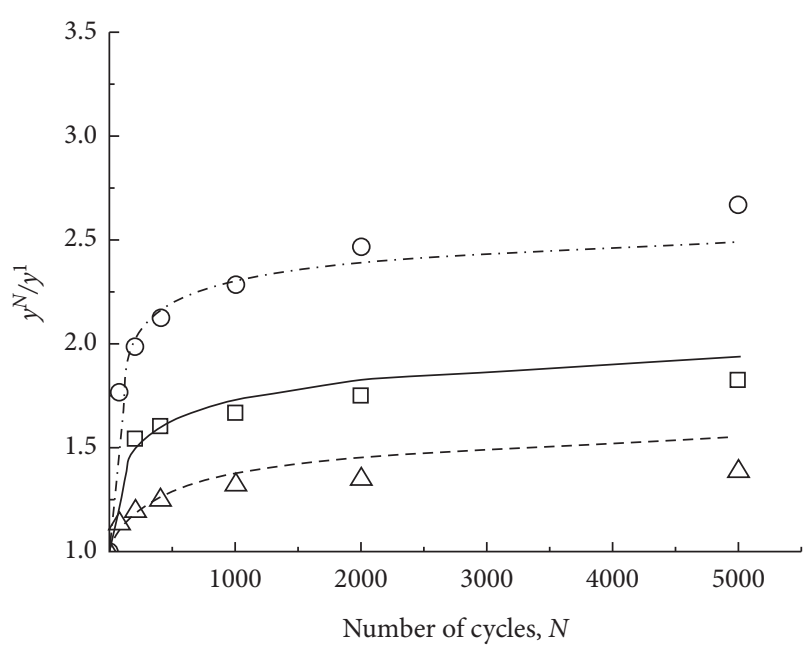

$\begin{array}{ll}\text { Test results in [11] } & \text { Prediction of } \\ \triangle 0.3 P_{\mathrm{u}} & ---0.3 P_{\mathrm{u}} \\ \square 0.45 P_{\mathrm{u}} & -0.45 P_{\mathrm{u}} \\ \bigcirc 0.6 P_{\mathrm{u}} & --0.6 P_{\mathrm{u}}\end{array}$

FIGURE 8: Comparison between results of the proposed method and model test [11].

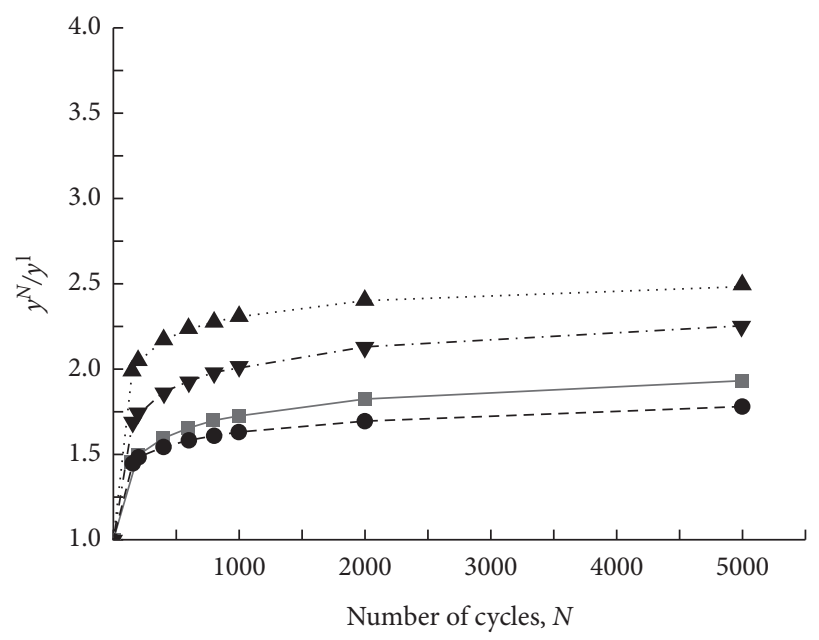

Consider the pore water Ignore the pore water pressure

$$
\begin{array}{ll}
-0.45 P_{\mathrm{u}} & -\bullet-0.45 P_{\mathrm{u}} \\
\text {.ム. } 0.6 P_{\mathrm{u}} & -\boldsymbol{\nabla}-0.6 P_{\mathrm{u}}
\end{array}
$$

FIGURE 9: Influence of cumulative pore water pressure on lateral displacement of pile.

displacement are increased by $9 \%$ and $13 \%$ relative to the method of ignoring the cumulative pore water pressure, respectively. It means that the cumulative pore water pressure has a negative effect on the development of pile displacement in soft clay, and this negative effect increases with the cyclic load amplitude. Therefore, it is necessary to consider the influence of cumulative pore water pressure in the analysis of cyclic laterally loaded pile, in the calculation

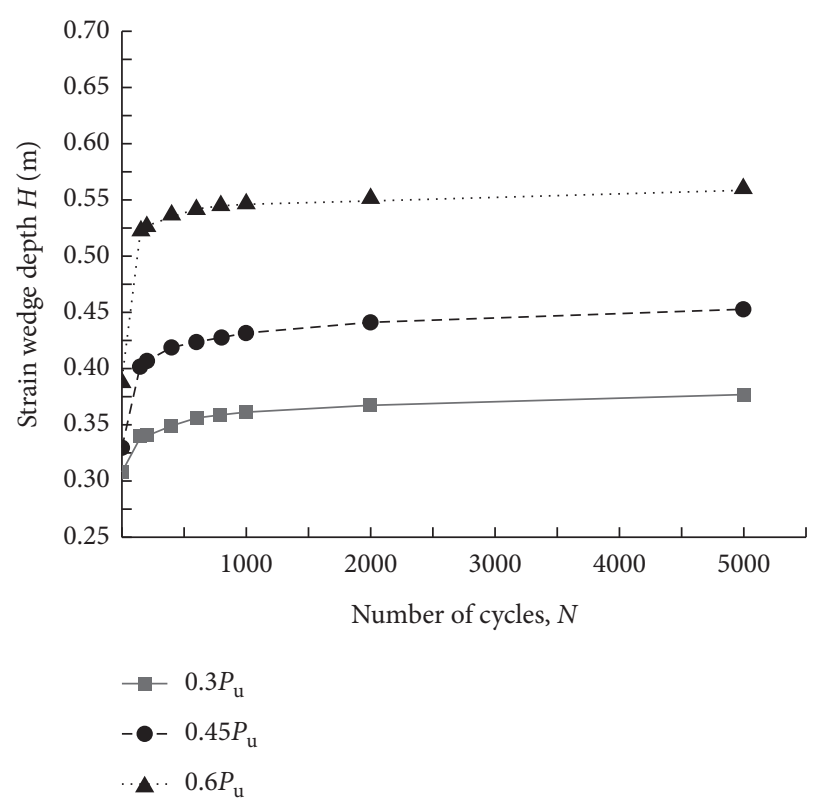

Figure 10: Influence of number of cycles on the depth of strain wedge.

response of pile in clay, which is also one of the main differences between clay subgrade and sandy subgrade under low-frequency cyclic loads.

Figure 10 illustrates the influence of the number of cycles on the depth of strain wedge. The strain wedge depth is an index reflecting the degree of bearing capacity of pile surrounding soil. It is found that the strain wedge depth increases as the number of cycles and cyclic load amplitude increase. This indicates that the degradation of soil in the upper strain wedge depth would lead to the deeper soil layers to participate in resisting lateral movement of pile shaft and exert its bearing capacity, which also reflects the working state of the soil-pile system under cyclic loads.

\section{Conclusions}

In this paper, a simplified method for the analysis of laterally loaded pile is proposed by combining a modified SW model with degradation model of soft clay. The effectiveness of the proposed method is verified by comparing with the results of $1 \mathrm{~g}$ model tests by Liao et al. [11]. Moreover, the study on the influence of pore water pressure implies that there is a need to consider the effect of cumulative pore water pressure during the analysis of cyclic laterally loaded pile embedded in soft clay. Finally, it is also found that the strain wedge depth increases as the number of cycles and cyclic load amplitude increase, which can reflect the working state of the soil-pile system under cyclic loads.

Compared with the finite element methods, the present method has a greater advantage in terms of calculation speed. Compared with $p-y$ curve method recommended by API, the present method can more effectively reflect the cyclic softening characteristics of pile surrounding and 
consider the influence of cyclic load characteristics. However, the research in this paper is currently only applicable to the cyclic loading conditions with constant amplitude. The calculation of pile under cyclic loading cases with variable amplitude still needs to be further studied in the future.

\section{Data Availability}

The data that support the findings of this study are available from the corresponding author, Wenbing $\mathrm{Wu}$, upon reasonable request.

\section{Conflicts of Interest}

The authors declare that they have no conflicts of interest regarding the publication of this study.

\section{Acknowledgments}

This research was supported by the National Natural Science Foundation of China (Grant nos. 51878634, 51678547, 51878185, and 41867034), the Outstanding Youth Project of Natural Science Foundation of Zhejiang Province (Grant no. LR21E080005), the Young Elite Scientists Sponsorship Program by CAST (Grant no. 2018QNRC001), and the Fundamental Research Funds for National University, China University of Geosciences (Wuhan) (Grant nos. 1910491T04 and CUGC09).

\section{References}

[1] H. G. Poulos, "Single pile response to cyclic lateral load," Journal of the Geotechnical Engineering Division, ASCE, vol. 108, no. 3, pp. 355-375, 1982.

[2] F. Y. Liang, H. B. Chen, and Y. J. Jia, "Quasi-static p-y hysteresis loop for cyclic lateral response of pile foundations in offshore platforms," Ocean Engineering, vol. 148, pp. 62-74, 2018.

[3] H. J. Li, L. Y. Tong, and S. Y. Liu, "Effect of excavation unloading on p-y curves for laterally loaded piles," Computers and Geotechnics, vol. 104, pp. 131-139, 2018.

[4] Y. P. Zhang, W. B. Wu, G. S. Jiang et al., "A new approach for estimating the vertical elastic settlement of a single pile based on the fictitious soil pile model," Computers and Geotechnics, vol. 134, Article ID 104100, 2021.

[5] A. J. Grashuis, H. A. Dietermann, and N. F. Zorn, "Calculation of cyclic response of laterally loaded piles," Computers and Geotechnics, vol. 10, no. 4, pp. 287-305, 1990.

[6] M. Achmus, Y. S. Kuo, and K. Abdel-Rahman, "Behavior of monopile foundations under cyclic lateral load," Computers and Geotechnics, vol. 36, no. 5, pp. 725-735, 2009.

[7] A. F. Hu, G. J. Zhang, Y. S. Jia, and X. D. Zhang, "Application of degradation stiffness model in analysis of cumulative lateral displacement of monopile foundation," Journal of Zhejiang University, vol. 48, no. 4, pp. 721-726, 2014.

[8] Y. P. Zhang, H. Liu, W. B. Wu, L. X. Wang, and G. S. Jiang, “A 3D analytical model for distributed low strain test and parallel seismic test of pipe piles," Ocean Engineering, vol. 225, Article ID 108828, 2021.

[9] P. Jeanjean, "Re-assessment of p-y curves for soft clays from centrifuge testing and finite element modeling," in
Proceedings of the Offshore Technology Conference, pp. 1-23, OTC, Houston, TX, USA, May 2009, Article ID 20158.

[10] C. LeBlanc, G. T. Houlsby, and B. W. Byrne, "Response of stiff piles in sand to long-term cyclic lateral loading," Géotechnique, vol. 60, no. 2, pp. 79-90, 2010.

[11] W. M. Liao, J. Zhang, J. B. Wu, and K. Yan, "Response of flexible monopile in marine clay under cyclic lateral load," Ocean Engineering, vol. 147, pp. 89-106, 2018.

[12] M. Vucetic and R. Dobry, "Degradation of marine clays under cyclic loading," Journal of Geotechnical Engineering, vol. 114, no. 2, pp. 133-149, 1988.

[13] G. Norris, "Theoretically based BEF laterally loaded pile analysis," in Proceedings of the 3 rd international conference on numerical methods in offshore piling, pp. 361-386, Paris, France, May 1986.

[14] M. Ashour, G. Norris, and P. Pilling, "Lateral loading of a pile in layered soil using the strain wedge model," Journal of Geotechnical and Geoenvironmental Engineering, vol. 124, no. 4, pp. 303-315, 1998.

[15] M. Heidari, M. H. El Naggar, M. Jahanandish, and A. Ghahramani, "Generalized cyclic p-y curve model for analysis of laterally loaded piles," Soil Dynamics and Earthquake Engineering, vol. 63, pp. 138-149, 2014.

[16] L. Y. Xu, F. Cai, G. X. Wang, and K. Ugai, "Nonlinear analysis of laterally loaded single piles in sand using modified strain wedge model," Computers and Geotechnics, vol. 51, pp. 60-71, 2013.

[17] J. M. Duncan and C. Y. Chang, "Nonlinear analysis of stress and strain in soils," Journal of the Soil Mechanics and Foundations Division, vol. 96, no. 5, pp. 1629-1653, 1970.

[18] J. H. Qian and Z. Z. Yin, The Earthwork Principle and Calculation, Water Power Press, Beijing, China, 1995, in Chinese.

[19] Y. Kim, S. Jeong, and S. Lee, "Wedge failure analysis of soil resistance on laterally loaded piles in clay," Journal of Geotechnical and Geoenvironmental Engineering, vol. 137, no. 7, pp. 678-694, 2010.

[20] S. M. Gleser, Generalized Behavior of Laterally Loaded Vertical Piles. Laterally Loaded Deep Foundations: Analysis And Performance, ASTM STP, West Conshohocken, PA, USA, 1984.

[21] R. Z. Liang, W. B. Wu, F. Yu, G. S. Jiang, and J. W. Liu, "Simplified method for evaluating shield tunnel deformation due to adjacent excavation," Tunnelling and Underground Space Technology, vol. 71, pp. 94-105, 2018.

[22] K. Yang and R. Liang, "Numerical solution for laterally loaded piles in a two-layer soil profile," Journal of Geotechnical and Geoenvironmental Engineering, vol. 132, no. 11, pp. 14361443, 2006.

[23] Matlab, Computer Software, MathWorks, Natick, MA, USA, 2017.

[24] Y. Hsiung, "Theoretical elastic-plastic solution for laterally loaded piles," Journal of Geotechnical and Geoenvironmental Engineering, vol. 129, no. 5, pp. 475-480, 2003.

[25] T. J. Liu, X. R. Ge, and G. F. An, "Study of characteristics of saturated soft clay under uniaxial cyclic load," Chinese Journal of Rock Mechanics and Engineering, vol. 31, no. A01, pp. 3345-3351, 2012, in Chinese.

[26] G. L. Feng, X. T. Feng, B. R. Chen, Y. X. Xiao, and Y. Yu, “A microseismic method for dynamic warning of rockburst development processes in tunnels," Rock Mechanics and Rock Engineering, vol. 48, no. 5, pp. 2061-2076, 2015.

[27] J. C. Chai and N. Miura, "Traffic-load-induced permanent deformation of road on soft subsoil," Journal of Geotechnical 
and Geoenvironmental Engineering, vol. 128, no. 11, pp. 907-916, 2002.

[28] A. Sakai, L. Samang, and N. Miura, "Partially-drained cyclic behavior and its application to the settlement of a low embankment road on silty-clay," Soils and Foundations, vol. 43, no. 1, pp. 33-46, 2003.

[29] G. L. Feng, B. R. Chen, Q. Jiang, Y. X. Xiao, W. J. Niu, and P. X. Li, "Excavation-induced microseismicity and rockburst occurrence: similarities and differences between deep parallel tunnels with alternating soft-hard strata," Journal of Central South University, vol. 28, pp. 582-594, 2021.

[30] G. L. Feng, X. T. Feng, and Y. X. Xiao, "Characteristic microseismicity during the development process of intermittent rockburst in a deep railway tunnel," International Journal of Rock Mechanics and Mining Sciences, vol. 124, Article ID 104135, 2019.

[31] B. B. Broms, "Lateral resistance of piles in cohesive soils," Journal of the Soil Mechanics and Foundations Division, vol. 90, no. 2, pp. 27-64, 1964. 